\title{
PROSPEK PENGEMBANGAN INDUSTRI PERKULITAN \\ PADA PELITA VI
}

\section{oleh : Drs. D. KARYADI}

\section{ABSTRACT}

The leather industry is one of the strong competitive industry, as it comes from renewable natural resources.

Therefore, the leather indusry has good prospect to develop at the Pelita VI to be the industrial products export competitive.

To develope leather industry and leather products should be given closed attention and well managed, especially concerning raw material supply, quality and leather waste treatment.

\section{INTISARI}

Industri perkulitan merupakan salah satu industri berdaya saing kuat, karena berasal dari sumber daya alam yang dapat diperbaharui.

Oleh karena itu industri perkulitan mempunyai prospek untuk dikembangkan pada Pelita VI untuk dijadikan komoditi andalan ekspor hasilhasil industri.

Untuk mengembangkan industri kulit dan produk kulit perlu diperhatikan dan dikelola dengan baik, hal-hal yang berkaitan dengan penyediaan bahan baku kulit, mutu dan pengendalian limbah kulit.

\section{I.PENDAHULUAN}

Pembangunan Lima Tahun (PELITA) VI yang dimulai pada tanggal 1 April 1994 memiliki arti yang sangat penting bagi pembangunan ekonomi bangsa Indonesia, pertama karena pada periode ini ditargetkan Indonesia akan mencapai tahap lepas landas. Kedua Pelita VI merupakan tahapan lima tahun pertama dari Pembangunan Jangka Panjang (25 tahun) tahap kedua. Ketiga kondisi 
erekonomian dan perdagangan dunia sedang mengalami perubahan yang sagat mendasar dengan berakhirnya perang dingin dan terutama terciptanya lok-blok perdagangan regional yang saat ini masih sulit diperhitungkan damaknya bagi perekonomian Indonesia.

Kebutuhan perekonomian nasional dan penerapan strategi pembangun$n$ yang mengandalkan ekspor sebagai penggeraknya membuat Indonesia tidak apat mengesampingkan berbagai perkembangan yang terjadi didalam hubungn ekonomi antar bangsa-bangsa.

Dalam rangka mengantisipasi hal-hal tersebut, maka salah satu sasaran engembangan industri pada PELITA VI adalah mendorong pengembangan inustri yang berdaya saing kuat, yang mengolah sumber daya alam dalam negeri, rutama yang mengolah hasil pertanian, termasuk didalamnya industri penglahan hasil peternakan.

\section{KEADAAN INDUSTRI KULIT DAN PRODUK KULIT}

Potensi bahan baku kulit

Produksi kulit Indonesia sampai saat ini masih merupakan komoditi konensional seperti kulit sapi, kerbau, kambing dan domba, disamping sedang diembangkan kulit kelinci dan kulit babi.

Perkembangan produksi kulit selama PELITA V dari tahun ke tahun teus meningkat, yaitu 16.070 ton pada tahun $1989,16.120$ ton tahun $1990,16.603$ on tahun $1991,16.225$ ton tahun 1992 dan 19.664 ton tahun 1993, dengan erincian seperti terlihat pada tabel 1 .

abel 1 : Produksi Kulit Mentah Kering Tahun 1989 - 1993 (dalam ton)

\begin{tabular}{|l|c|c|c|c|c|}
\hline \multicolumn{1}{|c|}{ JENIS } & 1989 & 1990 & $1991^{*}$ & $1992^{* *}$ & $1993^{* * *}$ \\
\hline Sapi & 9.235 & 9.471 & 9.580 & 9.079 & 11.266 \\
Kerbau & 2.156 & 2.214 & 2.377 & 2.254 & 3.780 \\
Kambing & 3.143 & 2.913 & 2.851 & 3.122 & 2.963 \\
Domba & 1.545 & 1.522 & 3.795 & 1.770 & 1.853 \\
\hline Jumlah & 16.070 & 16.120 & 16.603 & 16.225 & 19.862 \\
\hline
\end{tabular}

Keterangan : $\quad{ }^{*}=$ Angka sementara

** = Angka perkiraan

*** = Sasaran Pelita V

Sumber : Dit. Bina Usaha Tani dan Pengolahan Hasil Ditjen Peternakan

Selain kulit mentah kering terdapat juga bahan baku kulit berupa kulit mentah garaman.

Produksi kulit mentah kering seperti di atas dihasilkan dari populasi ternak yang ada, yaitu seperti pada tabel 2 .

Tabel 2 Populasi Ternak Penghasil Kulit tahun 1989 - 1992

\begin{tabular}{|l|r|r|r|r|c|}
\hline JENIS TERNAK & 1989 & 1990 & $1991^{*}$ & $1992^{* *}$ & $\begin{array}{c}\mathrm{r}(\%) \\
89-92\end{array}$ \\
\hline Sapi potong & 10.094 & 10.410 & 10.410 & 10.887 & 2,6 \\
Kerbau & 3.225 & 3.335 & 3.311 & 3.409 & 1,9 \\
Kambing & 10.996 & 11.484 & 11.484 & 11.804 & 2,4 \\
Domba & 5.910 & 6.006 & 6.106 & 6.223 & 1,7 \\
Babi & 6.939 & 7.136 & 7.700 & 7.062 & 5,2 \\
\hline Jumlah & 16.070 & 16.120 & 16.603 & 16.225 & 19.862 \\
\hline
\end{tabular}

Keterangan : * - Angka sementara

Sumber : Dit. Bina Program Ditjen Peternakan

Kebutuhan kulit pada tahun 1991 dapat digambarkan sebagai berikut :

- Kapasitas terpasang industri penyamakan kulit : 53,7 ribu ton *

- Kapasitas riil industri penyamakan kulit : 27, 0 ribu ton

- Ekspor kulit samak/processing : 1,4 ribu ton

- Produksi kulit mentah kering : 16,6 ribu ton

*) Sumber Ditjen Aneka Industri

Kekurangan bahan baku kulit mentah kering dipenuhi dari bahan baku kulit mentah garaman dan kulit impor.

Perkembangan volume dan nilai ekspor-impor kulit tahun 1988 - 1992 dapat dilihat pada tabel 3 .

Vol. X No. 19 Tahun 1993/1994 
abel 3. Ekspor-Impor Kulit Tahun 1988 - 1992

\begin{tabular}{|l|c|c|c|c|}
\hline \multirow{2}{*}{ AHUN } & \multicolumn{2}{|c|}{ EKSPOR } & \multicolumn{2}{c|}{ IMPOR } \\
\cline { 2 - 5 } & $\begin{array}{c}\text { Vol. Fisik } \\
\text { (ribu ton) }\end{array}$ & $\begin{array}{c}\text { Nilai } \\
\text { (000 US\$) }\end{array}$ & $\begin{array}{c}\text { Vol. Fisik } \\
\text { (ribu ton) }\end{array}$ & $\begin{array}{c}\text { Nilai } \\
\text { (000 US\$) }\end{array}$ \\
\hline 1988 & $3.081,0$ & $65.294,1$ & $1.884,7$ & $7.533,3$ \\
1989 & $2.300,2$ & $60.627,4$ & $1.735,5$ & $30.598,5$ \\
1990 & $2,821,7$ & $52.269,0$ & $2.051,9$ & $40.100,6$ \\
1991 & $1.406,6$ & $37.250,8$ & $10.186,7$ & $100.256,7$ \\
1992 & $4.255,3$ & $52.917,5$ & $59.967,5$ & $81.770,6$ \\
\hline
\end{tabular}

umber : Dit. Bina Program, Ditjen Peternakan

\section{Industri Kulit dan Produk Kulit}

Dalam rangka mendorong pengembangan industri pengolahan kulit dan barang jadi kulit didalam negeri, maka pemerintah melalui Keputusan Menteri Perdagangan Nomer : 306/Kp/X/86 tanggal 18 Oktober 1986 yang sudah dirubah dengan Keputusan Meneri Perdagangan Nomer : 177/Kp/VI/ 92 serta Keputusan Menteri Keuangan Nomer : 534/KMK.013/1992, tanggal 25 Mei 1992 yang mengatur tentang tata niaga ekspor kulit, dianggap merupakan alat pemacu dalam meningkatkan ekspor produk barang jadi kulit.

Posisi industri perkulitan nasional pada tahun 1992 adalah sebagai berikut : (lihat Tabel 2 dan 3 ).

abel 2. Kelompok Industri Kecil

\begin{tabular}{|l|c|c|c|}
\hline No. Jenis Industri & Unit Usaha & Tenaga Kerja & $\begin{array}{c}\text { Nilai Produksi } \\
\text { (Rp. 000) }\end{array}$ \\
\hline $\begin{array}{l}\text { 1. Penyamakan } \\
\text { Kulit }\end{array}$ & 489 & 2.853 & 7.021 .650 \\
$\begin{array}{l}\text { 2. Sepatu/Alas } \\
\text { Kaki }\end{array}$ & 4.579 & 22.034 & 12.774 .436 \\
$\begin{array}{l}\text { 3. Barang Jadi } \\
\text { Kulit }\end{array}$ & 3.385 & 14.506 & 47.410 .406 \\
\hline Jumlah & 8.453 & 39.393 & 67.206 .492 \\
\hline
\end{tabular}

Sumber : Ditjen Industri Kecil
Industri kecil perkulitan pada tahun 1988 berjumlah 7.924 unit usaha dan pada tahun 1992 berkembang menjadi 8.453 unit usaha. Industri kecil perkulitan tersebar di 19 propinsi dan hampir $89 \%$ berlokasi dipulau Jawa, sedangkan selebihnya berada diluar pulau Jawa.

Sistem produksi industri kecil perkulitan umumnya masih dilakukan secara semi kerajinan. Demikian pula mesin/peralatan yang digunakan umumnya masih sederhana dan dengan ketrampilan yang turun temurun. Namun dengan sebagian kecil yang telah menggunakan mesin/peralatan dengan teknologi madya, sehingga hasil produknya mampu menembus pasar ekspor.

Dalam upaya mengembangkan industri kecil perkulitan telah didirikan beberapa sarana pendukung, antara lain 3 Unit Pelayanan Teknis (UPT) penyamakan kulit, 3 UPT sepatu/alas kaki dan 2 UPT barang jadi kulit.

Selain UPT yang telah lama membina industri kecil perkulitan melalui pendidikan dan pelatihan adalah Balai Besar Penelitian dan Pengembangan Industri Barang Kulit, Karet dan Plastik yang ada di Yogyakarta.

Tabel 3. Kelompok Aneka Industri

\begin{tabular}{|c|c|c|c|c|}
\hline NO. & Jenis Industri & Unit Usaha & Tenaga Kerja & \multicolumn{1}{|c|}{ Kapasitas/tahun } \\
\hline 1. & Penyamakan kulit & 97 & 12.330 & 70.994 ton \\
2. & Sepatu/alas kaki & 96 & 40.462 & 86.635 pasang \\
3. & Barang jadi kulit & 70 & 22.232 & 69.972 buah \\
\hline & Jumlah & 263 & 75.024 & - \\
\hline
\end{tabular}

Sumber : Ditjen Aneka Industri

Industri perkulitan di Indoensia dalam perkembangannya dikelompokkan dalam kelompok industri yang berciri resources based industry dan labor intensive industry.

Pengembangan industry perkulitan di Indonesia menunjukkan pertumbuhan yang pesat, ini tampak dari nilai ekspor produk kulit sejak tahun $1989 \mathrm{~s} / \mathrm{d}$ 1992 pada tabel 4.

Tabel 4. Ekspor Produk Kulit (dalam US \$ 000)

\begin{tabular}{|l|c|c|c|c|}
\hline \multicolumn{1}{|c|}{ Komoditi } & 1989 & 1990 & 1991 & 1992 \\
\hline Kulit jangat/mentah & $4,364,95$ & 949.98 & 823,74 & 78,18 \\
Kulit samak & $68,647,40$ & 63.548 .57 & $46,419,34$ & $57,054,88$ \\
Sepatu kulit & $38,075,24$ & 203.425 .35 & $426,532,62$ & $754,529.40$ \\
Barang jadi kulit & $21,884,75$ & 99.680 .72 & $102,752,40$ & $168,346.11$ \\
\hline
\end{tabular}

Sumber : BPS 
Dari tabel tersebut di atas menunjukkan kestabilan kenaikan nilai ekspor ejak 1989 s/d 1992 rata-rata sebesar 206,95\% untuk sepatu kulit, dan 99,389\% ntuk barang jadi kulit, sedangkan untuk kulit jangat/mentah mengalami peurunan rata-rata sebesar $442,32 \%$.

\section{PROSPEK PENGEMBAGNAN INDUSTRI PERKULITAN \\ PADA PELITA VI}

\section{A. Kebijaksanaan Pemerintah}

Strategi pembinaan dan pengembagnan indusuri perkulitan nasional sesuai kebijaksanaan Departemen Perindustrian diarahkan pada :

1. Pendalaman struktur industri dan meningkatkan keterkaitan serta keterpaduan kegiatan dibidang pemotongan hewan, pengumpul/pengawet kulit, industri penyamakan kulit besar dan kecil, industri bahan kimia untuk penyamakan, industri sepatu/alas kaki besar dan kecil serta industri barang jadi kulit besar dan kecil, industri mesin/peralatan penyamakan kulit, sepatu/alas kaki dan industri kompoenn dan bahan penolong untuk sepatu/alas kaki dan barang jaadi kulit.

2. Peningkatan produksi baik mutu, maupun volume produk kulit dan barang jadi kulit, sehingga semua kegiatan industri penyamakan akan memasarkan produksinya berupa kulit jadi.

3. Mengembangkan industri pendukung (mesin-mesin perkulitan, komponen sepatu dan accessoriesnya).

4. Peningkatan ekspor produk perkulitan berupa produk kulit jadi dan barang jadi kulit.

Pengembangan industri kulit dan produk kulit banyak terkait dengan peningkatan ekspor kulit dan produk kulit.

Dalam rangka meningkatkan daya saing ekspor barang jadi kulit di pasaran Internasional, maka usaha dan kerja sama Pemerintah dan dunia usaha perlu terus ditingkatkan.

Kebijaksanaan Pemerintah yang dilakukan selama ini dalam meningkatkan ekspor barang jadi kulit memeperlihatkan hasil yang menggembirakan, untuk itu pada masa mendatang Pemerintah diharapkan akan terus membantu melalui kebijaksanaan-kebijaksanaan yang mengarah untuk terus memperlancar kegiatan sejak dari penyediaan bahan baku, proses produksi, sarana transportasi sampai proses pemasarannya.

Diharapkan pemerintah akan terus berusaha untuk menyempurnakan ketentuan yang ada melalui Paket Deregulasi sejauh masih ada hal-hal yang masih 
ghambat dalam kegiatan ekspor maupun untuk memenuhí kebutuhan babaku yang diperlukan oleh dunia usaha.

Dari dunia usaha diharapkan terus berusaha meningkatkan kualitas prosi dengan mutu yang sesuai dengan selera pasar, termasuk masalah disain harus ditingkatkan dan disempurnakan. Efisiensi dalam proses produksi harus terus diupayakan. Masalah perdagangan saat ini makin banyak dikan dengan masalah yang berhubungan dengan lingkungan hidup.

Dalam proses pengolahan kulit banyak menggunakan bahan-bahan kimia g dapat merusak lingkungan, oleh karena itu perlu segera diantisipasi oleh ustri pengolahan kulit, juga pencinta lingkungan yang mempermasalahkan dagangan binatang langka, termasuk kulit reptil.

Menyadari perubahan pola konsumsi dinegara maju cenderung pada proyang bersahabat dengan lingkungan, maka dalam rangka mengurangi haman pemasaran produk Indonesia, terutama untuk tujuan ekspor ke negara u perlu dipersiapkan dengan baik. Bagi eksportir kulit dan barang jadi kulit us mengikuti pola konsumsi yang cenderung pada produk yang bersahabat gan lingkungan.

\section{Penyediaan Bahan Baku Kulit}

Kebijaksanaan pengembangan agro industri peternakan dimaksudkan untuk mengembangkan penyediaan bahan baku hasil ternak (termasuk kulit) untuk industri hasil ternak agar dapat meningkatkan nilai tambah dan penyediaan lapangan kerja.

Selama Pelita VI populasi ternak penghasil kulit yaitu sapi potong, kambing, domba serta babi diproyeksikan seperti pada tabel 4 .

pel 4. Proyeksi Populasi Ternak Penghasil Kulit pada Pelita VI (1994 - 1998)

\begin{tabular}{|l|r|r|r|r|r|}
\hline ENIS TERNAK & \multicolumn{1}{|c|}{1994} & \multicolumn{1}{c|}{1995} & \multicolumn{1}{c|}{1996} & \multicolumn{1}{c|}{1997} & \multicolumn{1}{c|}{1998} \\
\hline pi potong & $11.094,9$ & $11.966,0$ & $12.348,9$ & $12.744,9$ & $13.151,8$ \\
erbau & $3.512,0$ & $3.564,7$ & $3.618,2$ & $3.672,5$ & $3.727,5$ \\
ambing & $12.280,0$ & $12.526,5$ & $12.777,0$ & $13.032,6$ & $13.293,2$ \\
omba & $6.411,1$ & $6.604,9$ & $6.604,9$ & $6.703,9$ & $6.804,5$ \\
abi & $8.719,9$ & $9,068,7$ & $9.431,4$ & $9.808,7$ & $10.201,0$ \\
\hline
\end{tabular}

mber : Dit. Bina Program Ditjen Peternakan
Dari tabel terlihat bahwa pada Pelita Vl, diproyeksikan semua jenis ternak penghasil kulit dapat meningkat rata-rata/tahun untuk masing-masing : Sapi potong $3,20 \%$, kerbau $1,50 \%$, kambing $2,00 \%$, domba $1,50 \%$ dan babi $4,00 \%$

C. Prospek Pengembangan Industri Perkulitan di Indonesia.

Prospek pengembangan industri perkulitan di Indonesia cukup baik karena hal-hal sebagai berikut :

- Peluang pasar ekspor kulit samak masih cukup terbuka luas.Perkembangan usahanya cukup baik, karena pasar dalam negeripun sangat potensial, sebagai akibat pesatnya pertumbuhan investasi industri sepatu/alas kaki dan barang jadi kulit. Disamping itu juga dampak meningkatnya permintaan komponen mesin/peralatan dari kulit teknis yang selama ini diimpor telah dapat dipenuhi dari dalam negeri.

- Berdasarkan data pemakaian sepatu perkapita masyarakat Indonesia baru mencapai sekitar 0,8 pasang/kapita/tahun. Hal ini menunjukkan masih terbukanya peluang pasar sepatu didalam negeri.

- Sejak diberlakukannya kebijaksanaan tata niaga ekspor kulit tahun 1986, maka terlihat perkemabngan kulit dan barang jadi kulit dari tahun ke tahun terus meningkat.

Proyeksi nilai ekspor untuk kulit jangat/mentah, kulit samak, sepatu kulit dan barang jadi kulit pada Pelita VI dapat dilihat pada tabel 5 .

Tabel 5. Proyeksi Nilai Ekspor pada Pelita VI (dalam US \$ 000)

\begin{tabular}{|c|c|r|r|r|}
\hline Tahun & $\begin{array}{c}\text { Kulit ja- } \\
\text { ngat/mentah }\end{array}$ & Kulit samak & Sepatu kulit & \multicolumn{1}{c|}{$\begin{array}{c}\text { Barang jadi } \\
\text { kulit }\end{array}$} \\
\hline $1994 / 1995$ & $30,156.00$ & $82,972.16$ & $954,168.32$ & $405,967.13$ \\
$1995 / 1996$ & $23,925.00$ & $106,584.44$ & $1,275,721.54$ & $527,757.27$ \\
$1996 / 1997$ & $19,140.00$ & $135,677.51$ & $1,560,291.40$ & $686,084.45$ \\
$1997 / 1998$ & $15,312.00$ & $171,429.28$ & $2,071,436.61$ & $891,909.79$ \\
$1998 / 1999$ & $12,250.00$ & $215,266.01$ & $2,475,559.13$ & $1,159,482.73$ \\
\hline
\end{tabular}

Sumber : Ditjen Aneka Industri

Walaupun ekspor kulit tiap tahun terus meningkat, tetapi jika diperhatikan ekspor kulit atasan dan barang jadi kulit Indonesia dibandingkan dengan impor/kebutuhan dunia terlihat share Indonesia masih kecil, ini membuktikan bahwa pangsa pasar dunia untuk kulit olahan dan produk barang jadi kulit masih cukup besar (lihat lampiran).

Vol. X No. 19 Tahun 1993/1994 


\section{Kesimpulan dan Saran}

Berdasarkan data terdahulu, maka dapat diberikan kesimpulan dan saran gai berikut :

\section{Kesimpulan}

1. Dalam rangka meningkatkan ekspor non migas, maka kulit dan produk kulit dapat menjadi salah satu andalan untuk dikembangkan.

2. Untuk pengembangan industri kulit dan produk kulit, maka perlu ditingkatkan mutu sumber daya manusia yang terkait dengan industri tersebut agar produk yang dihasilkan memenuhi syarat mutu dan dapat bersaing dipasar internasional.

3. Dengan berkembangnya industri kulit, khususnya industri penyamakan kulit, maka perlu diantisipasi limbah yang terjadi agar tidak mencemari lingkungan.

\section{Saran}

1. Tata niaga kulit agar diatur dengan bijaksana sehingga bahan baku kulit impor tidak menyebabkan industri kulit didalam negeri menjadi mati dan industri barang jadi kulit dapat bekerja dengan lancar, karena bahan baku kulit tersedia dan terjangkau daya belinya.

2. Untuk melepaskan ketergantungan dan harga yang tinggi dari bahanbahan kimia untuk penyamakan kulit yang masih diimpor, hendaknya dapat seluruh dibuat didalam negeri.

3. Dalam rangka peñanggulangan limbah industri kecil penyamakan kulit, maka hendaknya pemerintah membantu pembuatan unit pengolah limbah cair secará bertahap di sentra/industri kecil penyamakan kulit.
1. Departemen Perindustrian : Kebijaksanaan Pengembangan Industri pada Pelita VI

2. Direktorat Jenderal Aneka Industri : Prosek Industri Perkulitan dalam Era Pembangunan Jangka Panjang Tahap II

3. Direktorat Jendral Industri Kecil : Prospek Industri Kecil Perkulitan dalam Era Pembangunan Jangka Panjang Tahap II

4. Direktorat Jendral Perdagangan Luar Negeri Depertemen Perdagangan : Langkah-langkah Guna Memperkuat Daya Saing Industri Perkulitan di Indonesia

5. Drh. Soehadji, Direktur Jendral Peternakan : Pembangunan Pertenakan Dalam PJPT II, Depertemen Perianaian, Ditjen Peternakan 


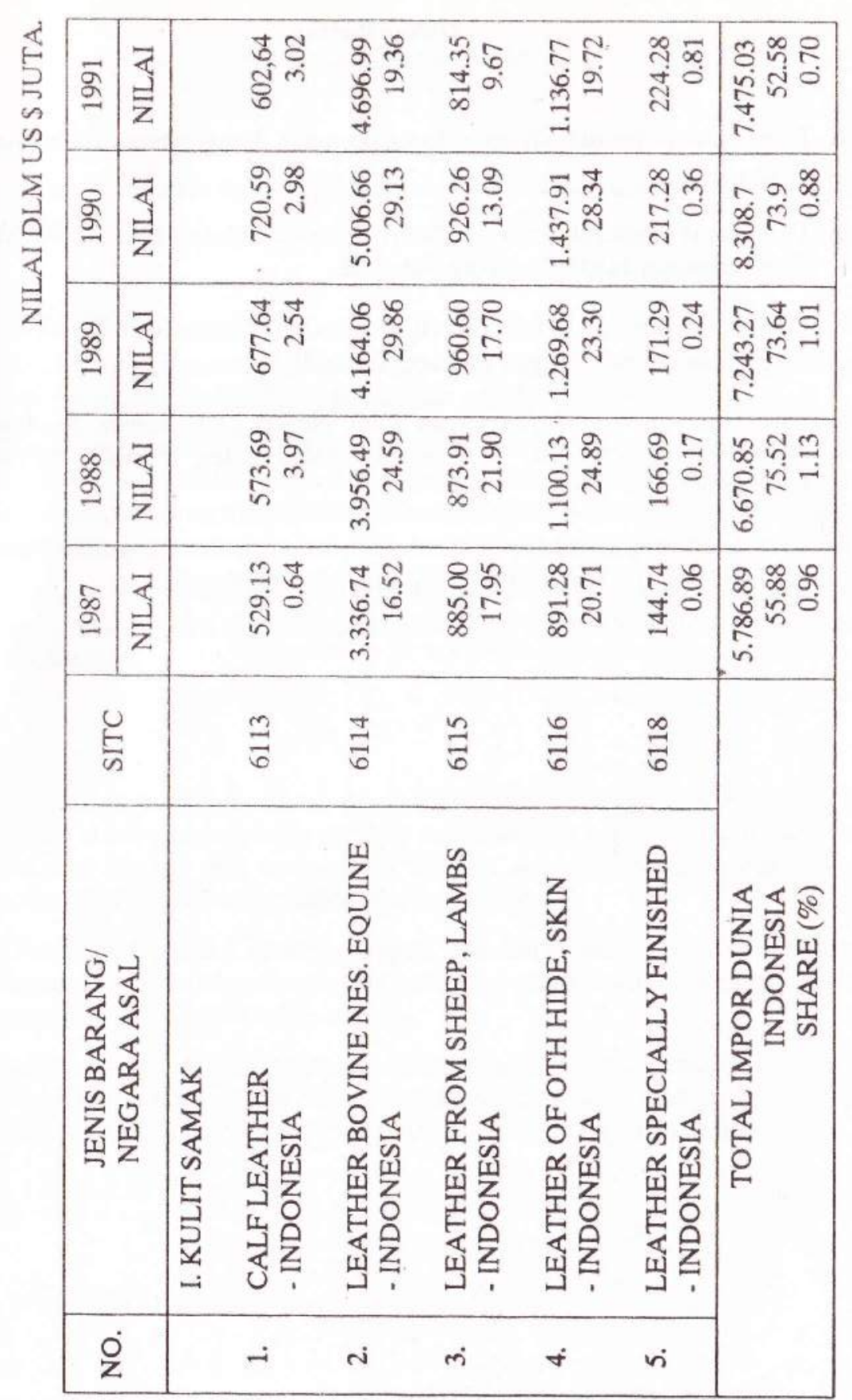

Majalah Barang Kulit, Karet dan Plastik

\begin{tabular}{|c|c|c|c|}
\hline 原 & & 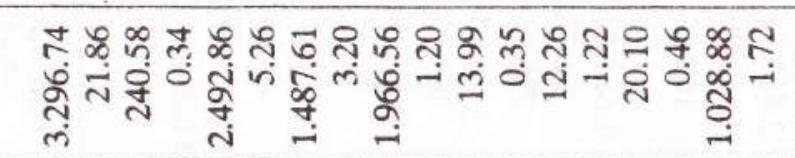 & 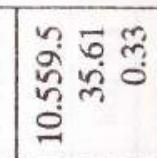 \\
\hline 市 & & 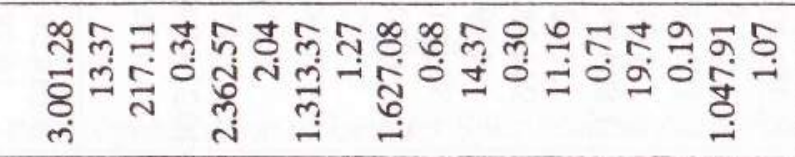 & 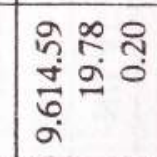 \\
\hline 承 & & 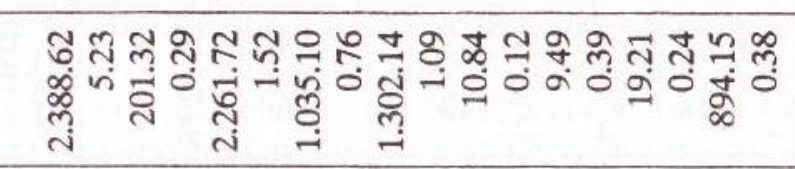 & 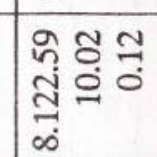 \\
\hline$\frac{\pi}{2}$ & & 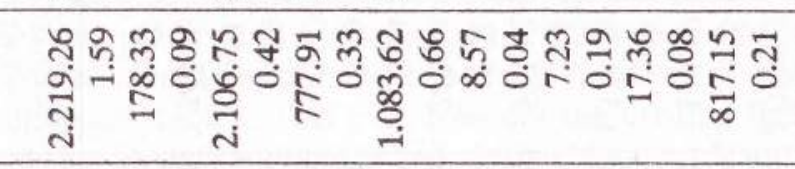 & 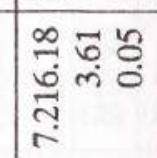 \\
\hline 尝 & & 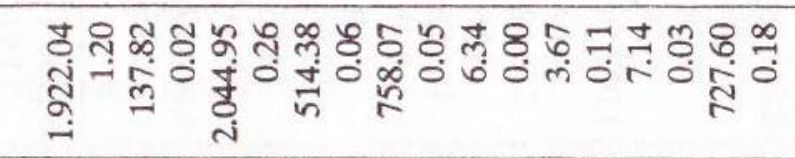 & 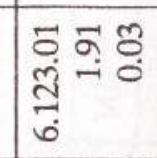 \\
\hline 㫐 & & $\frac{O}{\infty}$ & \\
\hline 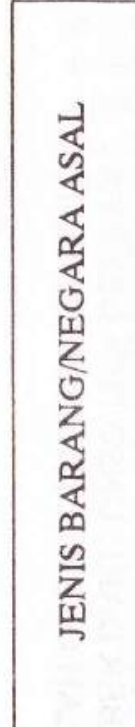 & 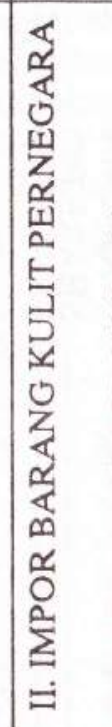 & 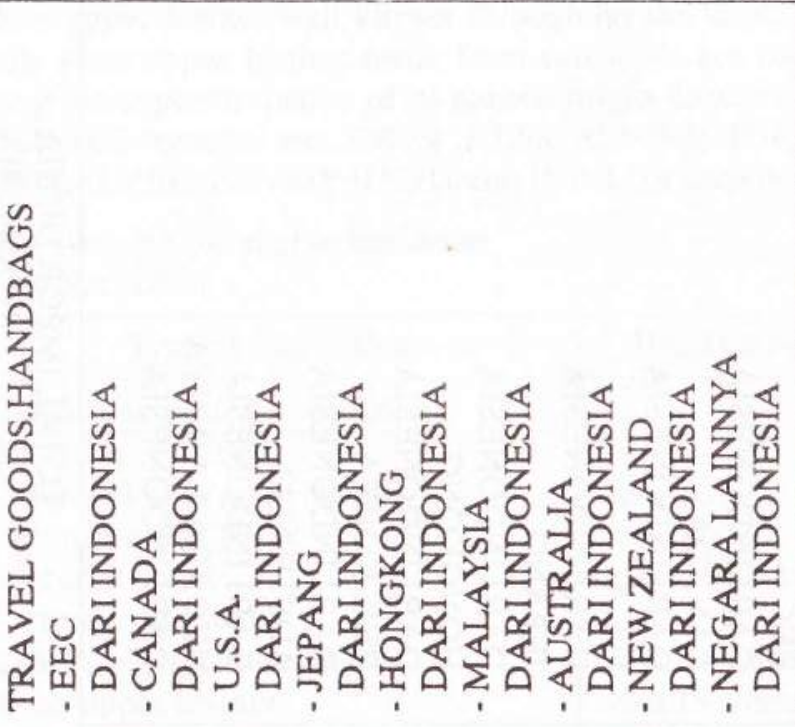 & 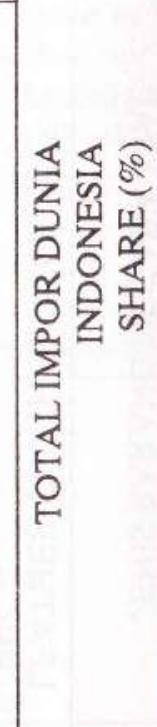 \\
\hline ¿ & & - & \\
\hline
\end{tabular}




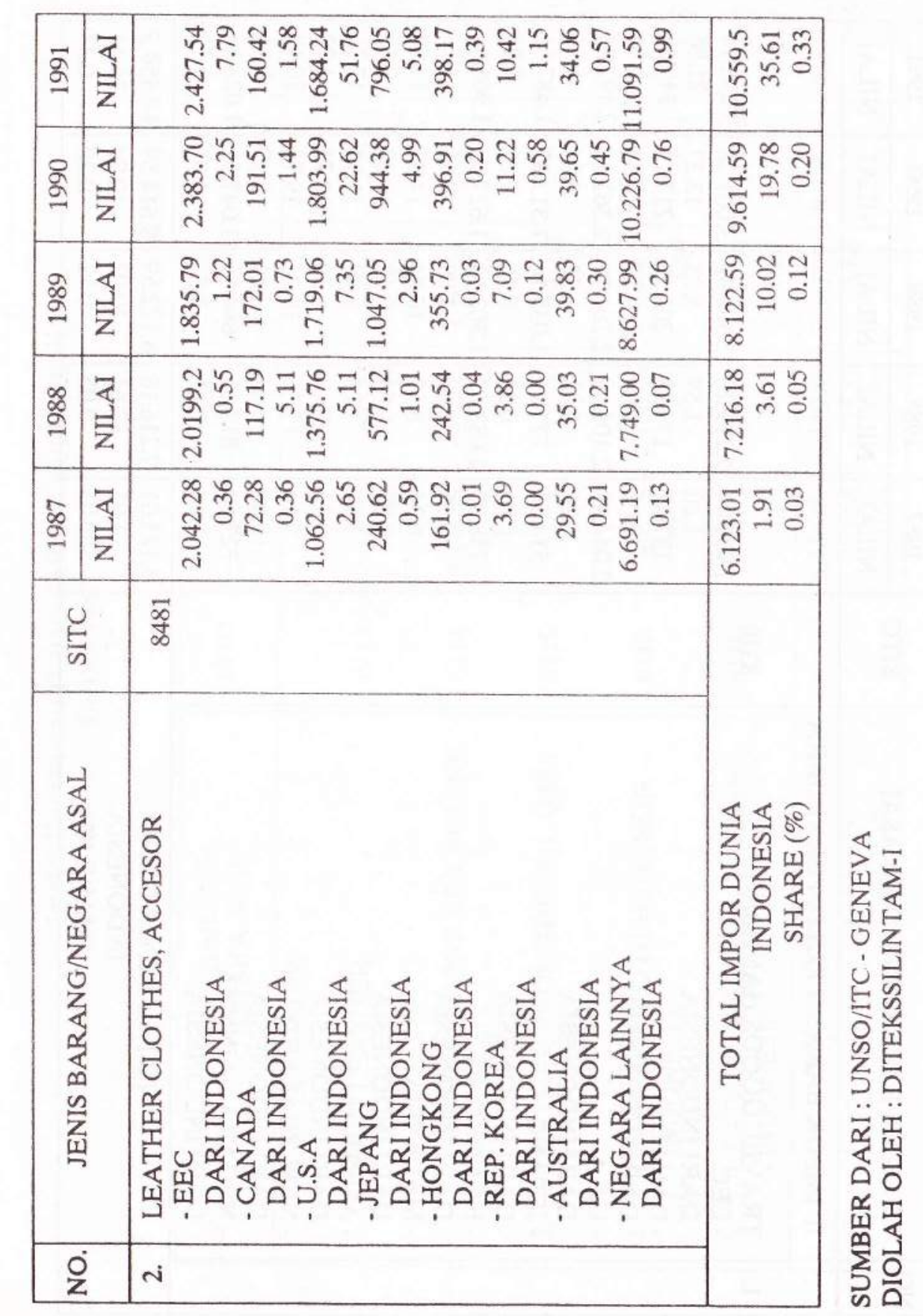

